\title{
The Research of Road Lighting Design in Three-dimensional Transportation
}

\author{
Lixiong Wang, Qinbo Li, Yuan Lei, Rui Dang ${ }^{1}$, Heng Liu \\ Tianjin Key Laboratory of Architectural Physics and Environmental Technology \\ Tianjin University \\ Tianjin China \\ Corresponding Author: Rui Dang, E-mail: dr_tju@163.com
}

\begin{abstract}
China is carrying out the development of three-dimensional transportation because of the advantages of overpasses. However, the researches of road lighting in China are based on the model of ordinary roads. Due to the lack of the research on the road lighting of three-dimensional transportation, this research's purpose is to abound basis and proposal of road lighting design of three-dimensional transportation. This study summarized the forms domestic three-dimensional transportation and typical road cross-section model, in order to propose different design principles and recommendations according to the different forms of roads.
\end{abstract}

Key words-three-dimensional transportation, typical road section, the arrangement of road lights, lighting design

\section{FOREWORD}

Road lighting system is an important part of traffic safety. Excellent road illumination can enhance the passage efficiency and reduce the possibility of accidents. It is an important part of urban night landscape as well. But the road lights arrangements of traditional single sided or double sided is based on the design of traditional road which have no elevation variation in road sections, so that these can't fully meet the light environment requirements of illumination uniformity, glare of pavement of the threedimensional transportation whose section has elevation changes. This article firstly analyzes the characteristics of three-dimensional traffic roads and lighting design difficulties to put forward four kinds of traffic typical section model design of three-dimensional transportation; Secondly, through field research combined with software simulation to propose reasonable arrangement of road lights for typical section model.

\section{ROAD LIGHTING MODELING OF THREE-DIMENSIONAL TRANSPORTATION}

Three-dimensional forms of transport, including viaducts, deep grooves roads with height difference of the landscape corridor and many other forms, are very complex. To sum up, however, the most influential factor on road lighting is the horizontal distribution and vertical elevation among different lanes. Spatial relationships between different lanes not only determine the light distribution, but also affected pedestrian or driver's line of sight distribution on the three-dimensional traffic road sections.

According to the basic functions division of the road, a road sections of typical three-dimensional transportation model should be include into three parts: the upper road, the lower road and the connection part.
According to the difference of relative position on the upper and lower sections of the road, section can be divided into two kinds: the rising middle section and the intermediate concave sections (such as groove path) (Figure 1).

There are three kinds of relative relationship on the projections plan of upper and lower sections: intersecting, tangency and displacement. And the transition zone has corresponding changes, including vertical transition, slope-type transition and the upper lane blocked driveway (Figure 2).

Two factors that the horizontal distribution and vertical elevation among different lanes combine with each other, producing the following typical road lighting models of three-dimensional transportation:

1). Deep groove sections whose transfer area is vertical concrete walls. Typical examples: North Fourth Ring road with deep groove.

2). Sunken road surface whose transfer area is green slope. Typical examples: Fuchengmen flyover.

3). Three-dimensional transportation with pedestrian corridor above. Typical examples: GongZhuFen flyover.

4). Viaduct. Typical examples: HangTianQiao flyover.

After conducting field researches of four kinds of typical cross-sections, finding that there are several problems in current lighting design.

1). For three-dimensional transportation, because there is a certain degree of elevation difference, it's difficult to achieve effective illumination of the entire section with only two rows of lights.

2). For sunken road surface whose transfer area is green slope, the environment of green belt area is often easily overlooked.

3). For dimensional traffic roads with "shadow space" under the bridge, light source should be placed in corridors under the bridge or in bridge openings. At the same time, symbolic light source should be placed in the bridge hole for prompt.

4). For sections whose transfer area is vertical concrete walls and the projections of the upper and lower sections road are tangent, because the position in elevation difference lack buffer zones, such as isolation belt, the major problem is the mutual interference by lights on different height of the road.

5). If you have placed the lower side of the road pavement lighting, illumination of sidewalks may be high on one side than the motor vehicle lanes. Easier for the driver to detect moving objects in the road outside of the area, so risk of accidents will be small[1]. 


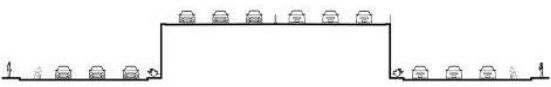

(a) rising middle section

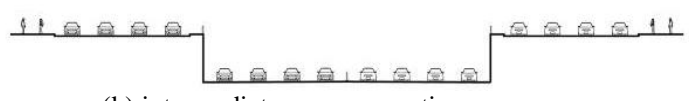

(b) intermediate concave sections

Figure 1. Relative position on the upper and lower sections of the road (Source: drawn from the author)

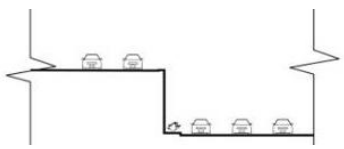

(a) vertical transition

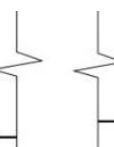

(b) slope-type transition

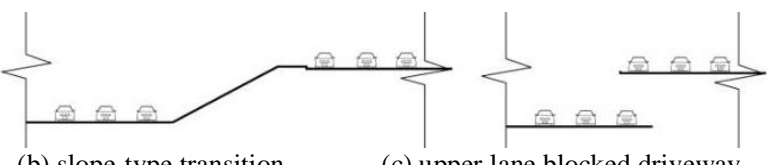

(c) upper lane blocked driveway

Figure 2. The three main forms of transition region (Source: drawn from the author)

\section{REASONABLE DESIGN PATTERN OF LIGHTING OF THE TYPICAL SECTION}

\section{A. The Basic Principle Methods of Lamp Distribution}

Section forms of three-dimensional transportation are plenty. But through the summary, we discover the commonalities of them. First, According to the basic principles of road planning, we know that faster speed main roads are arranged in middle of the road and the slower speed roads are distributed on both sides of the road. Second, the dividing line of the road elevations difference is the line between the main roads with side road, and between the motor vehicle lanes with non-motorized vehicle lanes. Accordingly, the selections of location of lamp distribution on road cross section have following principles.

1) In order to enhance the visual inducing effect of vehicle, the locations where the characteristics of the lane suddenly change in the road cross section, like the junction of upper and lower roads and the junction of motor vehicle road and non-motor vehicle road, are the major area to place lighting facilities(Figure 3).

2) Considering the contradiction on the arrangement of road lights between the glare and illumination. In general, when the width of side road is less than $7.5 \mathrm{~m}$, the two-way street lights are placed on each junction of two roads to reduce the glare interference on the upper road that caused by the lower road. Meanwhile, upper and lower road lights use the staggered arrangement to solve the problems of illumination non-uniformity. When the width of side road is more than $7.5 \mathrm{~m}$ ( 3 or 4 lanes), road lights on the side road should be placed on the side away from the main road.
3) Through using extra lights to fill the area that can't be effectively covered by road lighting. If the sloping green belt between two roads has transport function, its landscape lighting should be given some attention. We should enhance the environment difference of the green belt areas to ensure the safety of pedestrians. If there are corridors or bridge openings for vehicles or pedestrians under the upper road, auxiliary lighting facilities should be placed in "shadow space", such as metal halide lamp.

\section{B. Suggestion for Typical Section Design}

1) Deep groove sections whose transfer area is vertical concrete walls. (Figure 5)

1) The main road lighting equipment is placed in the edge of the road, and lights of the side road are decided by many factors.

2) Placing road lights on the side near the main road, which can have a beneficial impact of the threshold increment on the lanes near the main road.

3) Place road lights on the side near the main road and use the dislocation arrangement to set road lights of upper and lower roads, so that upper lights can make up the glare problem and illumination non-uniformity of the lower road.

4) In the inlet and outlet area of groove roads, upper lights should be placed on the side away from the main road.

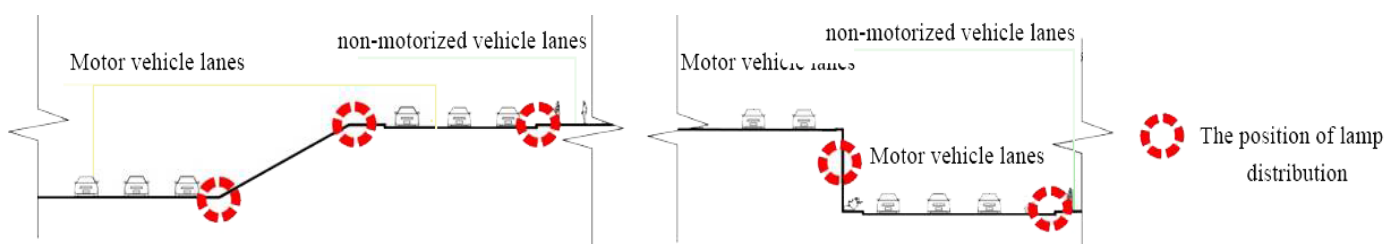

Figure 3. The position of lamp distribution on road section (Source: drawn from the author)

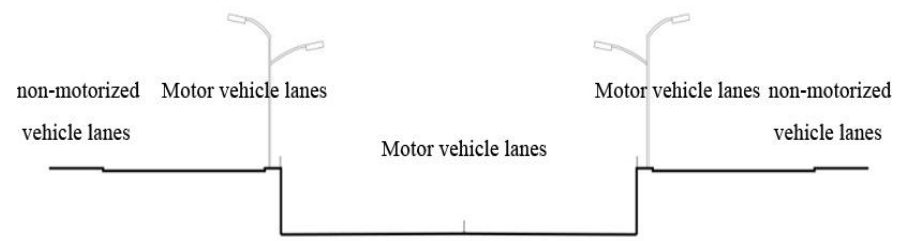

Figure 4. The position of lamp distribution on deep groove sections (Source: drawn from the author) 
2) Sunken road surface whose transfer area is green slope. (Figure 5)

1) In general, the influence of upper lights on lower lights won't make the increment threshold of the lower road over the standard requirement.

2) Whether upper lights placed on the side near the pavement or on the side near the lower road is decided by their level of Horizontal and vertical illuminance on the pavement. If the motor vehicle road of upper road has two lanes, the road lights should be placed on the side away from the pavement to provide higher illuminance. If the motor vehicle road of upper road has three or more lanes, the use of the back light to illuminate the pavement may have a better effect.

3) Landscape illumination need to be set in the green belt as supplemental lighting.

3) Three-dimensional transportation with pedestrian corridor above.(Figure 6)

1) If the road is relatively wide, we should arrange double-headed lamp to let as much light as possible to irradiate into space of the pavement, meanwhile, take technical measurements on light fixtures to prevent too much glare.

2) If the road is relatively narrow, we can set spotlights the wall or the top plate of the pavement to light. In addition, we can also use low-pole lights for the lighting of the motor vehicle road.

\section{4) Viaduct(Figure 7)}

1) When the width of the side road is less than three lanes, road lights should be placed on the side of the viaduct. Using the staggered arrangement to improve illumination uniformity. When the auxiliary road has three or four lanes, road lights can be placed on the side away from the viaduct.

2) In the inlet and outlet area of groove roads, whether the lower road has more than three lanes or not, upper lights should be placed on the side away from the main road.

3) If there are corridors for passage under the viaduct, it's proper to set metal halide for supplemental lighting.

\section{CONCLUSION}

1) Three-dimensional roads model can be simplified and classified and summarized as several typical road sections.

2) In the lighting design of three-dimensional transportation where main road and side roads are parallel, we should regard roads which have elevation difference as a whole to design and simulate.

3) We should pay attention to the areas that can't be effectively covered by light, such as should add auxiliary lighting to sloping green belt, bridge corridors and bridge openings.

4) In the lighting design stage, complex three-dimensional traffic road sections whose main road and side roads are parallel can be simplified.

\section{ACKNOWLEDGEMENTS}

This article is supported by a program of Tianjin Natural Science Foundation - The research of LED road lighting effect and energy saving in photopic vision mesopic vision, the item No. 10JCYBJC03800

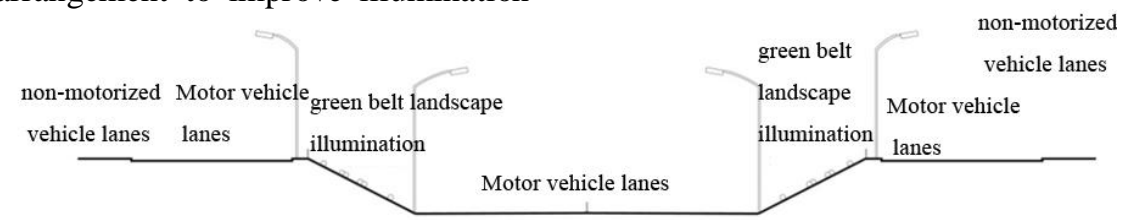

Figure 5. The position of lamp distribution on Sunken road surface (Source: drawn from the author)

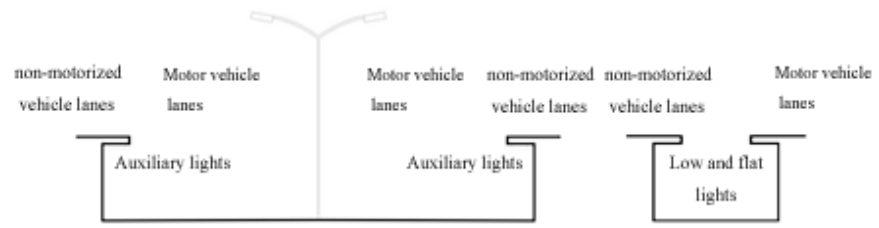

Figure 6. The position of lamp distribution on three-dimensional transportation (Source: drawn from the author)

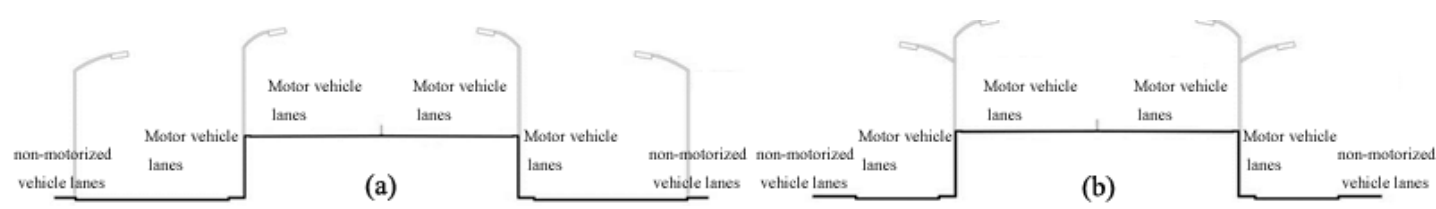

Figure 7. The position of lamp distribution on viaduct (Source: drawn from the author)

[1] MATLAB-based analysis of urban road lighting environment ratio, Rongping Wang, Rongqing Jiang, Tonghui Zhao, Rong Wang, 